\title{
EXERCISES WITH INCREASING AND DECREASING MUTUAL DISTANCE BETWEEN THE TWO COURTYARDS IN DEVELOPING THE ACCURACY OF THE SERVE IN TENNIS
}

\section{Istanbul / Türkiye \\ p. 106-115}

Received: $30 / 11 / 2021$

Accepted: $10 / 12 / 2021$

Published: 01/01/2022

This article has been scanned $t$ iThenticat No plagiarism detected

\author{
Hasan Ch Sabar AL-DULAIMI ${ }^{1}$ \\ Abduljalil Mouloud Abduljalil ALBAYATI ${ }^{2}$ \\ Mohammed Madallah Saloom ALRAWI ${ }^{3}$
}

\begin{abstract}
:
The research aims to identify the importance of the exercises used in the research using exercises with increasing and decreasing distance on both sides of the court, the aim of which is to develop the accuracy of the transmission in ground tennis, which is one of the most important skills of the game of tennis, as the experimental method was used for its suitability and the nature of the research, the research sample included the team of the University of Anbar In tennis for the academic year (2020-2021), they were chosen deliberately, and the following statistical methods were used: arithmetic mean, standard deviation, t-test for linked samples, t-test for unrelated samples and percentage The researchers reached the following conclusion The development of the accuracy of the serve skill in tennis.
\end{abstract}

Key words: Tennis, Exercises, The Team of The University of Anbar In Tennis.

http://dx.doi.org/10.47832/2717-8293.15.8

(iD) Researcher, Anbar University, Iraq, ssanchsabar@gmail.com, https://orcid.org/0000-0003-1637-371X 
تمرينات بتزايد الممسافة وتناقصها المتبادلين بين ساحتي الملعب في تطوير دقة الإرسال بالتنس الأرضي

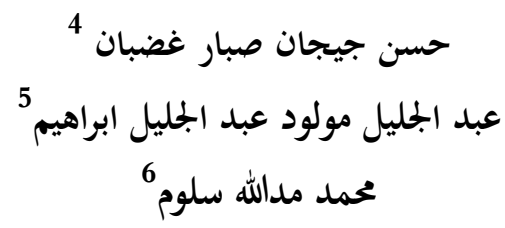

الملخص:

يههف البحث في التعرف على أهمية التمرينات المستخدمة في البحث باستخدام تمرينات بتزايد المسافة وتناقصها

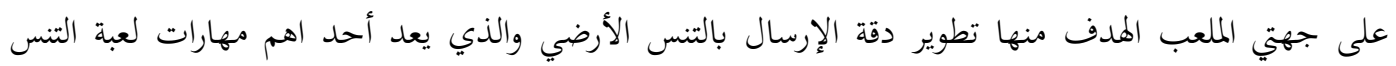

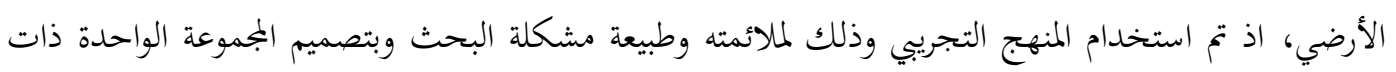

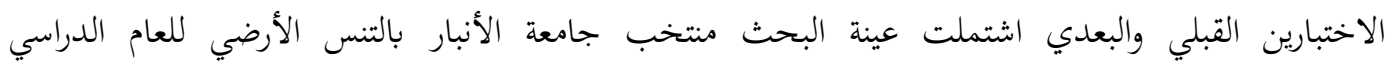
(2020-2021) وتم اختيارهم بصورة عمدية، وتم استخدام الوسائل الإحصائية الآتية: المتوسط الحسابي لإبياري والانحراف المعياري واختبار(ت) للعينات المرتبطة وقد توصل الباحثان إلى الاستنتاجات الآتية: - تطور دقة مهارة الإرسال بالتنس الأرضي.

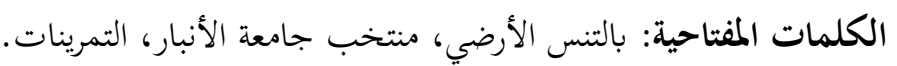




\section{الفصل الأول}

1

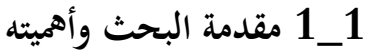

إن ما يشهده العالم من تقدم كبير في جميع بجالات الحياة لا يأتي من فراغ وانما يأتي نتاج دراسات وبكوث يقوم بها الباحثين

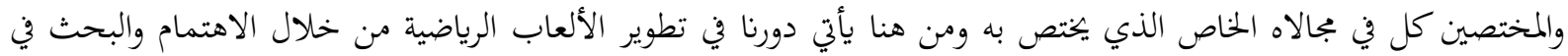

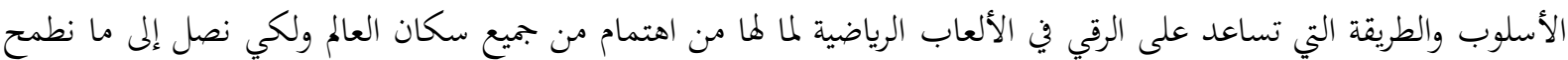
به كمختصين في المجال الرياضي يجب التفكير بشكل خاص بكل لعبة لا وبكل مهارة على حده ولكل مهارة من مهارات الألعاب حيث يذكر (ماهر محمد العامري 2014)" ان المدربين يسعون دائما إلى تطبيق افضل الطرائق التعليمية والتدريبية التي من خلالها يستطيع المدرب أو المدرس الوصول باللاعب أو المتعلم المبتدئ الأفضل مستوى ممكن في الأداء المهاري من خلال المال

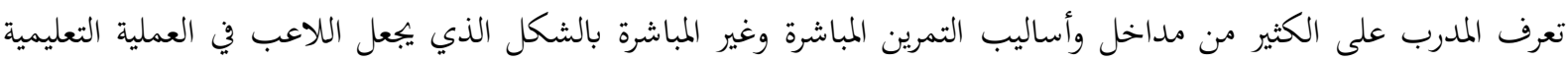

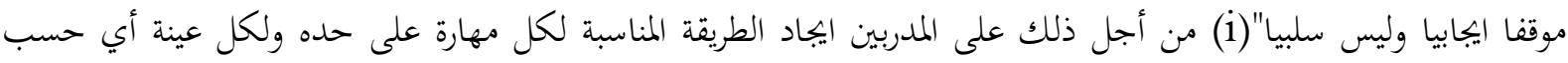
مستوى وعمر العينة المستهلفة من أجل الاختصار في الجهد المبذول والوقت لان ذلك يساعد على الاستفادة من المدة الزمنية التي يبدأ فيها المنافسة وخاصة في الألعاب الفردية وهي ما سوف يتم استهدافه في هذا البحث لان الألعاب الفردية تحتاج إلى اهتمام أكبر من الألعاب الجماعية لان اللاعب يحتاج إلى تدريب خاص يستهدف نقاط الضعف ويعالجها ويقوي نقاط القوة لدى اللاعب ومن هنا جات أهمية البحث الحالية وذلك باستخدام تمرينات بتزايد المسافة وتناقصها المتبادلين بين ساحتي الملعب في تطوير دقة الإرسال عند اللاعب باعتبار الإرسال من المهارات المغلقة التي تكون ادائها متوقف على اللاعب ومدى تركيزه وارتفاع

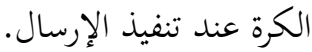

\section{2}

إن لعبة التنس الأرضي تحتاج إلى تركيز كبير من اللاعب لأفها يجب ان تؤدى بسرعة ودقة متناهية أي انه هناك ترابط كبير

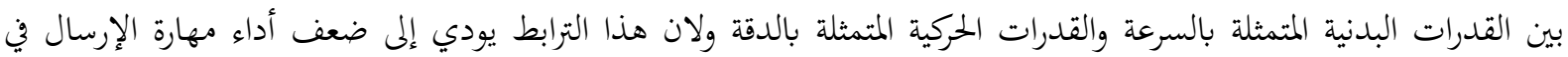

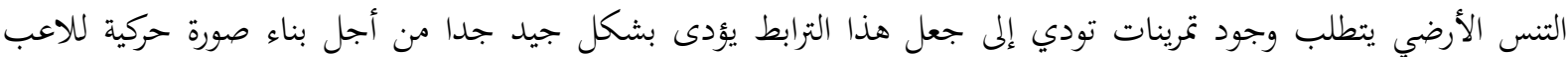
تحاكي الإرسال، ومن هنا جاءت مشكلة البحث، لذى ارتأى الباحثان إلى وضع تمرينات بتزايد المسافة وتناقصها المتبادلين بين ساحتي الملعب في تطوير دقة الإرسال بالتنس الأرضي.

\section{1}

التعرف على تأثير التمرينات بتزايد المسافة وتناقصها المتبادلين بين ساحتي الملعب في تطوير دقة الإرسال بالتنس الأرضي.

هناك فروق ذات دالة احصائية بين الاختبارات القبلية والبعدية لمجموعة البحث التجريبية في تطوير دقة الإرسال بالتنس 
1 1_5 مجالات البحث.

1 1_5_1 البجال البشري: منتخب جامعة الأنبار للتنس الأرضي.

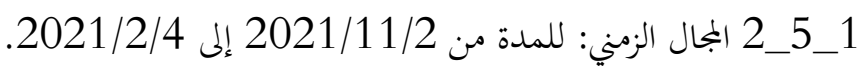

1 3_5_5 المجال المكاني: ملعب الأنشطة الطلابية في جامعة الأنبار.

الفصل الثاني

2- 2 - منهجية البحث وإجراءاته الميدانية:

2-2 1-2 1 nنهج البحث:

استخدام الباحث المنهج التجريبي وذلك لملائمته وطبيعة مشكلة البحث وبتصميم المجموعة الواحدة ذات الاختبارين القبلي

والبعدي.

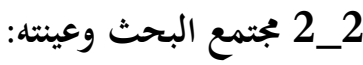

تم تحديد مجتمع البحث والتي تمثل بلاعبي منتخب جامعة الأنبار والبالغ عددهم (6) لاعبين،اما العينة فقد تم اختيارها

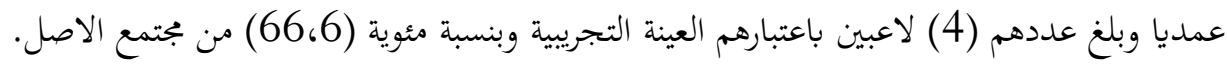

2_3 الأجهزة والأدوات ووسائل جمع المعلومات

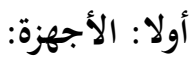

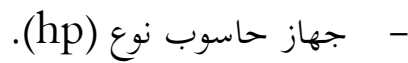

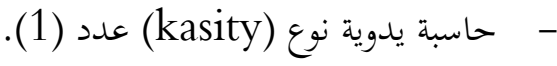

- ماعة توقيت نوع بابانية.

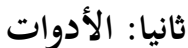

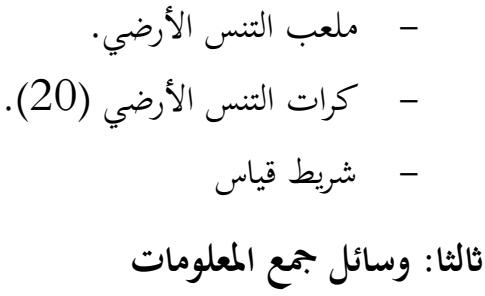

- - المصادر العربية والأجنبية.

- م الاختبارات والقياس.

2_4 تحديد متغير البحث واختباره

استهدف الباحث متغير الإرسال في لعبة التنس الأرضي لأنه يعتبر بداية لكل نقطة وتعتمد عليها اللعبة بشكل اساسي لا

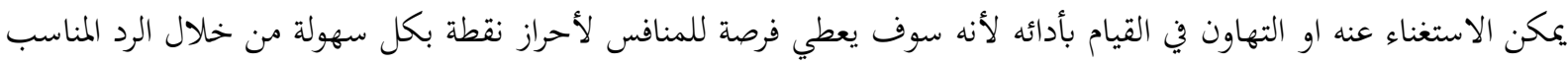




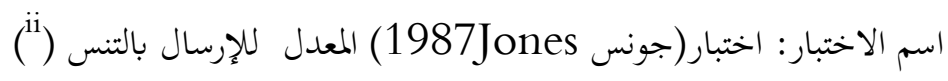 الغرض من الاختبار: لقياس القدرة المهارية والدقة لمهارة ضربة الإرسال.

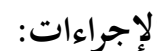

- - يتم تخطيط منطقة الإرسال كما هو موضح في شكل (2_1).

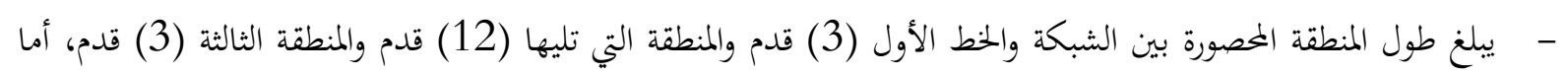

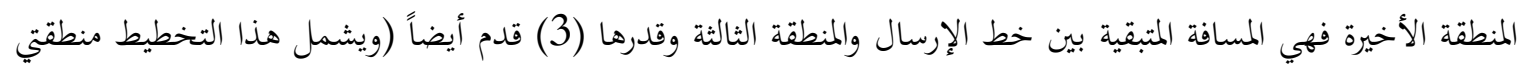

$$
\text { الإرسال اليمين واليسار). }
$$

- - البدء بالاختبار وذلك بان يقف المختبرين على شكل أزواج (كل زميلين) أحدهما يرسل والآخر يسترجع الكرات، ويعطى

$$
\text { لكل طالب (5) محاولات من كل جانب. }
$$

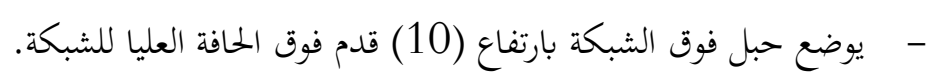

- - إذا عبرت الكرة من فوق الحبل تعطى نصف درجة التقييم المحددة على أرض الملعب الذي تسقط فيه الكرة.

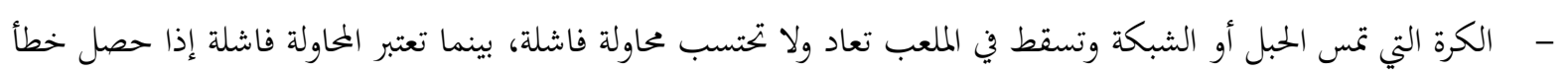

$$
\text { في الإرسال. }
$$

- - ميعى لكل طالب محاولتين للتمرين.

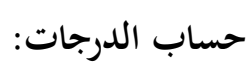

يتم اختيار أفضل محاولة من اليمين وأفضل محاولة من اليسار وبحمع الاثنان ويستخرج الوسط الحسابي لما.

\section{كيفية تسجيل الدرجات:}

- عند سقوط الكرة في المنطقة الأولى يحصل اللاعب على (2) درجة، أما سقوطها في المنطقة الثانية فيحصل على (4) درجة والمنطقة الثالثة (5) درجات أما المنطقة الأخيرة فيحصل على (6) لفئل (6) درجات. 


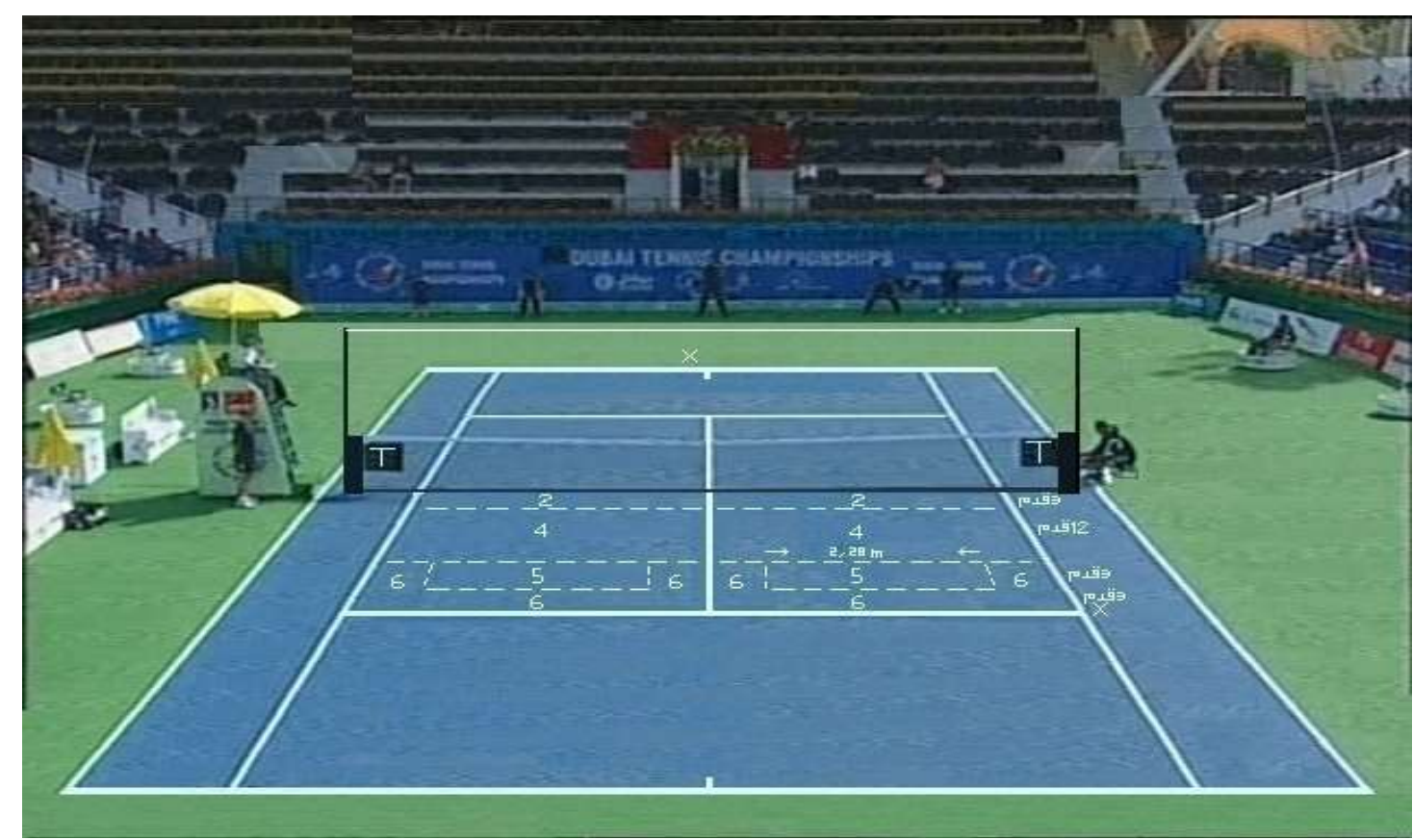

شكل رقم (1_1)

توضح الدرجات التقويمية ومناطق الدقة لاختبار (جونس)

لقياس أداء مهارة الإرسال

بعد اطلاع الباحث بتصميم تمرينات بتزايد المسافة وتناقصها المتبادلين بين ساحتي الملعب في تطوير دقة الإرسال بالتنس الأرضي، حيث قام الباحث بتقسيم المنطقة الخلفية إلى ثلاث مناطق متساوية بقياس 82، 1 طول

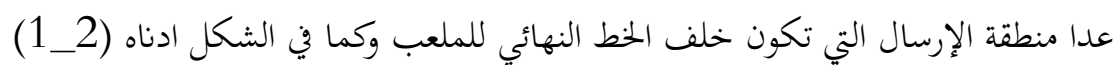

$\mathrm{d}$ g

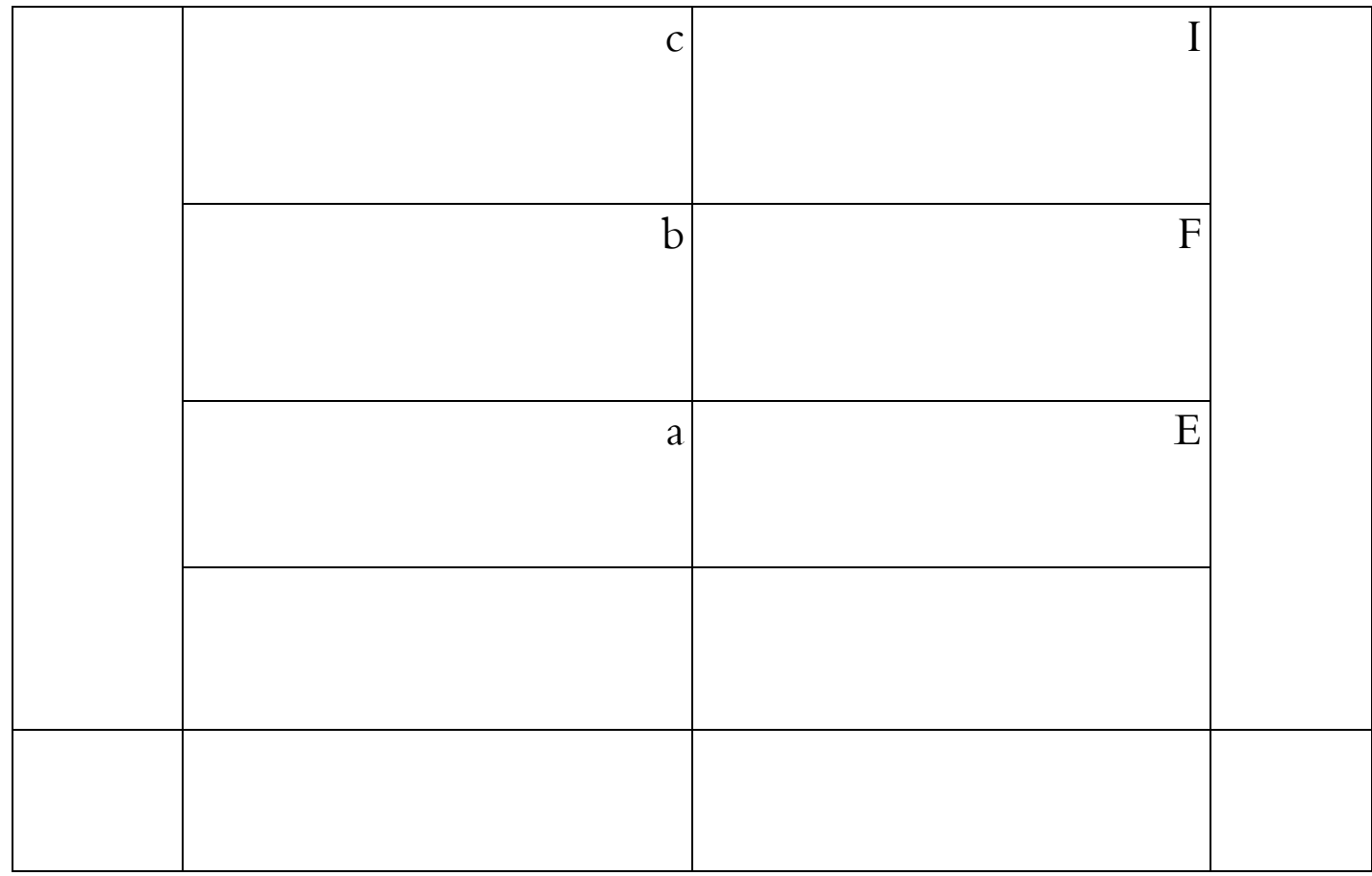




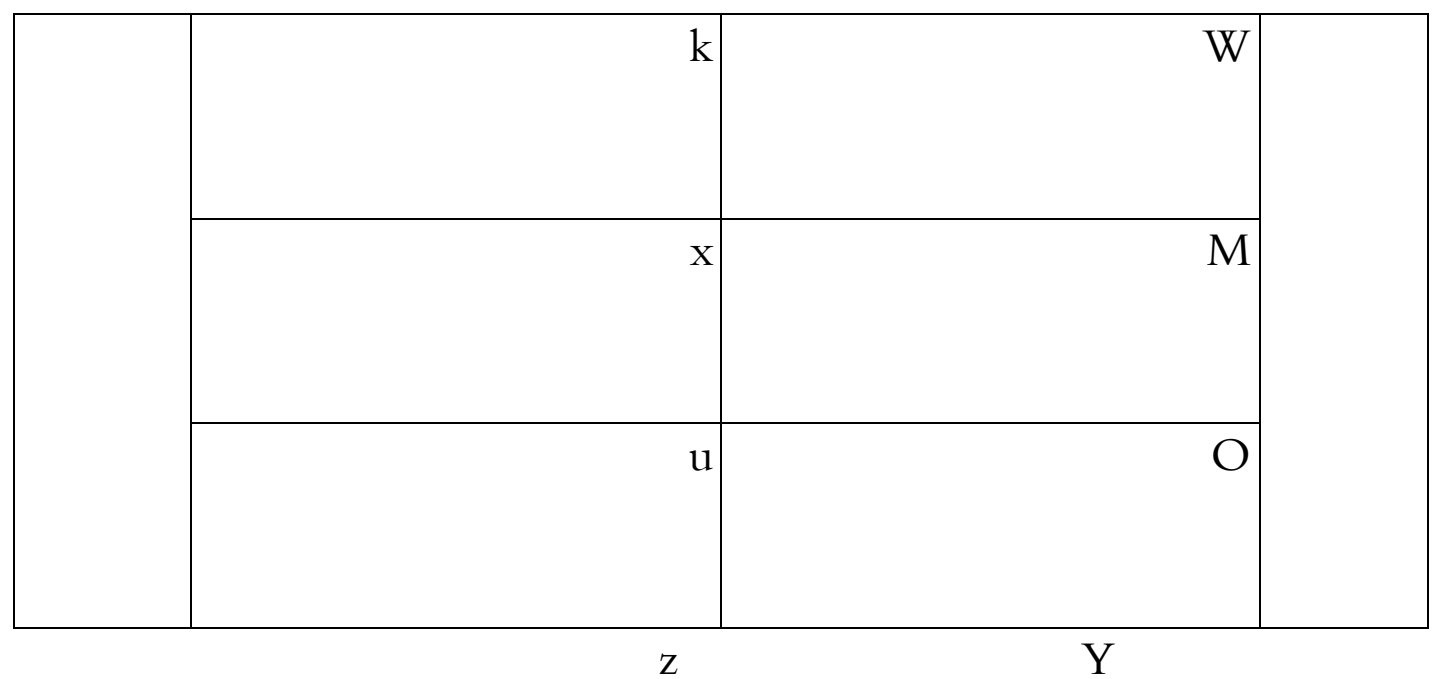

يرسل اللاعب من منطقة a إلى الملعب المقابل إلى منطقة O مرة إلى منطقة W مرة إلى منطقة W مرة وإلى منطقة الإرسال المخصصة حسب القانون.

يرسل اللاعب من منطقة b إلى منطقة O مرة إلى منطقة W مرة إلى منطقة W مرة وإلى منطقة الإرسال المخصصة حسب القانون. يرسل من منطقة C إلى O مرة وإلى W مرة إلى W مرة وإلى منطقة الإرسال المخصصة حسب القانون. يرسل من منطقة d إلى منطقة O مرة إلى W مرة إلى W مرة وإلى منطقة المخصصة للإرسال حسب القانون. ومن جميع المناطق المحددة في الملعب بالترتيب.

2_6 2

قام الباحث بأجراء الدراسة التجريبة الأولية على عينة قبل الدخول في الدخول في البرنامج المعد من قبل الباحث من أجل

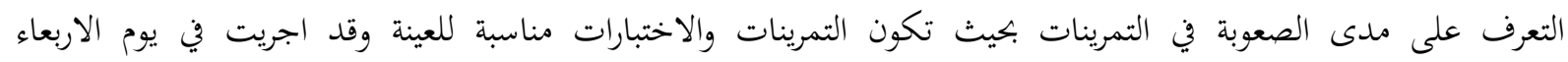
2020/11/4 على للاعبين من منتخب الجامعة. هـ2

2_1_2 قام الباحث باجراء الاختبارات القبلية لمجموعة البحث التجريبية يوم الخميس 5 / 11/ 2020 لمتغير الإرسال في لعبة التنس الأرضي.

\section{2_2_2}

بدأ الباحث باجراء تجربة البحث الرئيسية في يوم الأحد الموافق 8/ 11/ 2020 وذلك بتطبيق تمرينات بتزايد المسافة

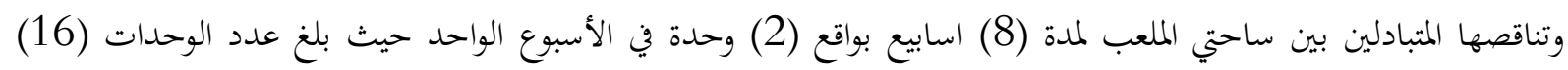
وحدة وقد تم الانتهاء من تجربة البحث الرئيسية يوم الاثنين الموافق (2021/1/4).

3_7_2

أجريت الاختبارات البعدية يوم الاربعاء الموافق 2021/1/6 لمهارة الإرسال في التنس الأرضي وقد أتبع الباحث نفس طريقة أداء الاختبارات القبلية والشروط ذاتحا. 
8_2

3-

3 1_1 عرض نتائج الاختبارات القبلية والبعدية وتحليلها ومناقشتها

جدول (1_3)

يبين الاوساط الحسابية للاختبارات القبلية والبعدية والوسط الحسابي للفروق وانخرافتها المعيارية وقيم (ت) المحسوبة والدلالة لمهارة الإرسال لمجموعة

البحث

\begin{tabular}{|c|c|c|c|c|c|c|c|c|c|}
\hline \multirow[t]{2}{*}{ الدلالة } & \multirow[t]{2}{*}{ ت المحسوبة } & \multirow[t]{2}{*}{ ع ف } & \multirow[t]{2}{*}{ س ف } & \multicolumn{2}{|c|}{ الاختبار البعدي } & \multicolumn{2}{|c|}{ الاختبار القبلي } & \multirow{2}{*}{ القياس } & \multirow[t]{2}{*}{ المتغير } \\
\hline & & & & $\varepsilon$ & س & $\varepsilon$ & س & & \\
\hline دال & 16.24 & $1 ، 49$ & $9 ، 91$ & 1.83 & 20.58 & $1 ، 21$ & $10 ، 66$ & نقطة & الإرسال \\
\hline
\end{tabular}

(ت) الجدولية (2،57) درجة الحرية (5) ومستوى دلالة (0605)

يبن الجدول (3_1) الخاص بالفروق بين الاختبارات القبلية والبعدية في مهارة الإرسال للتنس الأرضي لمجموعة البحث التجريبية وان قيمة (ت) المسوبة لمهارة الإرسال (16،24) وبما ان قيمة (ت) المحسوبة لمهارة الإرسال بالتنس الأرضي كانت أكبر

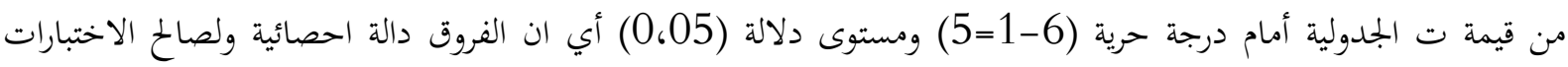
البعدية والذي يعزوه الباحث إلى التمرينات بتزايد المسافة وتناقصها المتبادلين بين ساحتي الملعب والتي ساعدت على المه تطوير دقة أداء الإرسال بالتنس الأرضي لما للتمرينات التي أعدت من قبل الباحث التي كانت قريبة من أداء المهارة او ساعدت علئ على أداء المهارة بشكل فعال بكيث كانت التمرينات بشكل متدرج ومختلف يحاكي واقع المهارة المراد تطويرها حيث تذكر (رشا طالب 2007) نقلا عن ابراهيم عصمت "ان التمارين اذا احسن انتقاؤها ووضع برابجها واستخدامها وتقويمها تستطيع ان تشوق اللاعب وتثير همته وتوسع خبراته وتساعده في الفهم فهي تشحذ الفكرة وتساعد في تعليم المهارات وفي تنمية الاتحاهات "(iii)

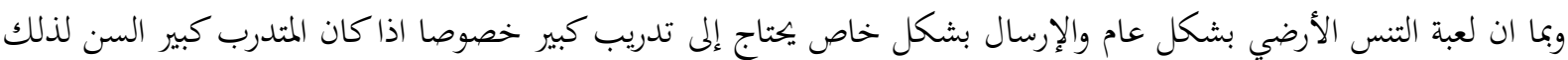

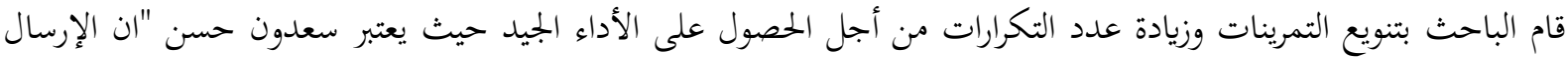
أكثر ضربة مركبة ومعقدة ومهمة في لعبة التنس وتحتاج لتدريب طويل لاتقاها ليعتاد الجسم على تحقيق التوافقات بين الاستناد جانبا على القدم الأمامية اليسرى للاعب اليد اليمنى ورمي الكرة باليد الآخرى في الهواء وحركة المضرب الصحيحة باليد الحاملة للمضرب وحركة القدم الآخرى في التقدم ودوران الجسم بقوس من دائرة والقفز في بعض الأحيان عند التسديد (iv) ومن ذلك

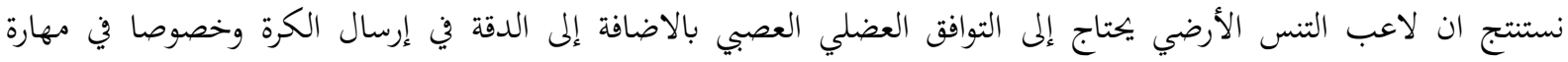
الإرسال والتي لا تاتي الا من خلال تمرينات تناسب مهارة الإرسال لاهما تعتبر من المهارات الهجومية للعبة حيث يعتبر رافد مهدي ان الإرسال "من مفاتيح اللعب الهجومي والقوة الضاربة في اللعب الحديث للتنس، واللاعب الذي يتميز بالقوة والدقة في الإرسال تكون فرصته كبير في كسب المبارة "(v) وعلى ذلك فان الإرسال يعتبر المهارة الاصعب في لعبة التنس الأرضي لان اللاعب عليه ان يشرك كل اعضاء جسمه في الإرسال من أجل جعل الإرسال بشكل يصعب مهمة استلام اللاعب المنافس للإرسال بالتالي يعطي اللاعب المرسل امكانية الحصول على نقطة بسبب الاستقبال الخاطئ للمنافس او الحصول على نقطة من خلال الإرسال

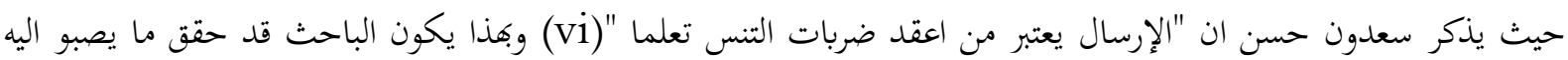
من هدف البحث وفرضيته. 


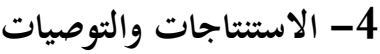

1-4 1-4 (لاستنتاجات

1- التمارين بتزايد المسافة وتناقصها المتبادلين بين ساحتي الملعب حققت تاثير اييابيا في تطوير الإرسال في التنس الأرضي. 4 4

1 ضــرورة اعتماد التمرينات بتزايد المسافة وتناقصها المتبادلين بين ساحتي الملعب في تعلم وتطوير الإرسال في التنس الأرضي. 2_ اجراء بحوث ودراسات آخرى في تعلم وتدريب في مهارات اللعبة وألعاب آخرى مشاهمة. 3_ ضرورة اجراء دراسات آخرى على فئات عمرية أكبر ولكلا الجنسين. 
ماهر محمد عواد العامري:فسيلوجيا التعلم الحركي، ط1، النبراس للطباعة والتصميم، 2014. P 62،os Angles 1987، 1، A. Measure of Tennis Serving Ability، S. K،2_Jones رشا طالب ذياب: استخدام تمارين مقترحة في نقل اثر التعلم لليد المفضلة وغير المفضلة لمهارة التصويب في كرة السلة، رسالة

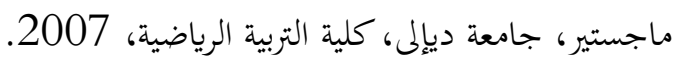

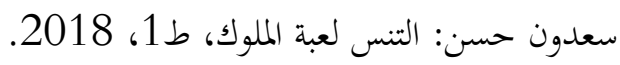
رافد مهدي قدوري: جوهر التنس الأرضي، ديإلى مطبعة جامعة ديإلى، 2013.

i - ماهر حمد عواد العامري :فسيلوجيا التعلم الحركي , ط1 , النبراس للطباعة والتصميم, 2014 ,ص214 .

P 62 ،os Angles 1987 ، 1، A . Measure of Tennis Serving Ability ، S . K ، (1) Jones-ii

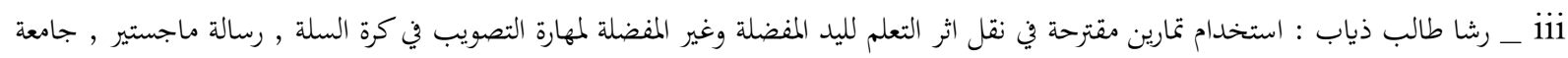

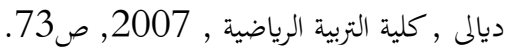

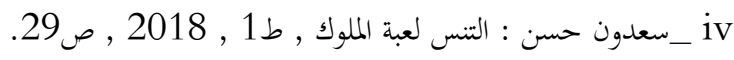

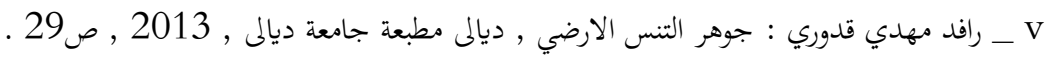

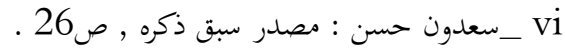

